\title{
Cancer patients' needs during hospitalisation: a quantitative and qualitative study
}

\author{
Marcello Tamburini*1, Laura Gangeri ${ }^{1}$, Cinzia Brunelli ${ }^{1}$, Paolo Boeri ${ }^{1}$, \\ Claudia Borreani1, Marco Bosisio1, Claude Fusco Karmann², \\ Margherita Greco ${ }^{1}$, Guido Miccinesi ${ }^{1}$, Luciana Murru ${ }^{1}$ and Patrizia Trimigno ${ }^{1}$
}

Address: ${ }^{1}$ Predictive and Preventive Medicine, Istituto Nazionale Tumori, Via Venezian, 1, 20133 Milan, Italy and ${ }^{2}$ Italian League Against Cancer, Via Venezian, 10, 20133 Milan, Italy

Email: Marcello Tamburini* - tamburini@istitutotumori.mi.it; Laura Gangeri - gangeri@istitutotumori.mi.it;

Cinzia Brunelli - brunelli@istitutotumori.mi.it; Paolo Boeri - boeri@istitutotumori.mi.it; Claudia Borreani - borreani@istitutotumori.mi.it; Marco Bosisio - bosisio@istitutotumori.mi.it; Claude Fusco Karmann - c.fusco@legatumori.mi.it;

Margherita Greco - mgreco@istitutotumori.mi.it; Guido Miccinesi - g.miccinesi@cspo.it; Luciana Murru - luciana.murru@istitutotumori.mi.it; Patrizia Trimigno - trimigno@istitutotumori.mi.it

* Corresponding author

Published: 23 April 2003

BMC Cancer 2003, 3:12
Received: 5 February 2003

Accepted: 23 April 2003

This article is available from: http://www.biomedcentral.com/I47/-2407/3//2

(C) 2003 Tamburini et al; licensee BioMed Central Ltd. This is an Open Access article: verbatim copying and redistribution of this article are permitted in all media for any purpose, provided this notice is preserved along with the article's original URL.

\begin{abstract}
Background: The evaluation of cancer patients needs, especially during that delicate period when they are hospitalized, allows the identification of those areas of care that require to be improved. Aims of study were to evaluate needs in cancer inpatients and to improve the understanding of the meanings of the needs expressed.
\end{abstract}

Methods: The study was conducted during a "sample day", with all the cancer patients involved having been hospitalized at the Istituto Nazionale Tumori of Milan (INT) at least 48 hours beforehand. The study was carried out using quantitative and qualitative methodologies. The quantitative part of the study consisted in making use of the Needs Evaluation Questionnaire (NEQ), a standardized questionnaire administered by the INT Psychology Unit members, supported by a group of volunteers from the Milan section of the Italian League Against Cancer. The aim of the qualitative part of the study, by semi-structured interviews conducted with a small sample of 8 hospitalized patients, was to improve our understanding of the meanings, implications of the needs directly described from the point of view of the patients. Such an approach determines the reasons and conditions of the dissatisfaction in the patient, and provides additional information for the planning of improvement interventions.

Results: Of the 224 eligible patients, $182(81 \%)$ completed the questionnaire. Four of the top five needs expressed by $40 \%$ or more of the responders concerned information needs (diagnosis, future conditions, dialogue with doctors, economic-insurance solutions related to the disease). Only one of the 5 was concerned with improved "hotel" services (bathrooms, meals, cleanliness). Qualitative analysis showed that the most expressed need (to receive more information on their future conditions) has the meaning to know how their future life will be affected more than to know his/her actual prognosis.

Conclusions: Some of the needs which emerged from this investigation could be immediately satisfied (the need for psychological support, the need for economic aid, the need for spiritual 
support), while others will have to be faced in the longer term; for example, the presence of a high percentage of needs in patient-physician relationships and/or information-communication issues, could be resolved by setting up structured introductory training courses for all clinicians in the institution. On the other hand, the needs related to the living infrastructure (bathrooms, meals, etc...) could encourage the Institution to improve its services.

\section{Background}

Over recent years an important change has taken place regarding the caring of patients. The biomedical model characterized by an objective approach to patients, which considers both their bodies and their diseases as objects, has been replaced by the "bio-psycho-social" model. This model is characterized by an approach that considers patients holistically and their disease as a complex event consisting in an alteration of the system at several different but integrated levels, biological, psychological and social [1-3].

This transformation in the field of medicine has taken place, above all, with regard to chronic and degenerative diseases such as cancer [4]. Facing a long course of a disease that is often susceptible to control but never to a complete recovery, evaluation of the "the best possible treatment" concerns aspects which are not only necessarily or strictly clinical (undesirable effects of treatment, years of survival). These further aspects are directly linked to the patients' quality of life, to personal aspirations, values, and quality of their relations and needs. For clinicians, examination of these aspects means that they need to pay more attention to the patients themselves as individuals during the various stages of their disease, beginning from diagnosis until the terminal phase. $[5,6]$.

Helping patients to make important decisions about their lives and their health means therefore helping them to be aware of the impact that different treatments may have upon their ability to look after their own families or continue to work [7-10].

Thus, in the caring of patients, an important task of the physician consists in informing him/herself and informing patients about what can be offered them in order to improve their independence and quality of life [7]. In order to reach this aim, the considerable amount of work that has been carried out on the development of instruments self-compiled by the patient, is in its own way an improvement upon the limits of physician centered evaluation of the physical, psychological and social problems of the patient. Doctors tended to attribute to these problems with their own personal hierarchy of values and priorities, which were, therefore, often truly different from the patients' own perceptions of the problems [11-15]. Furthermore, it has been observed that it is the patients' subjective evaluation of their illness, rather than scientific achievements in medicine, that play a major factor in determining their choices and decisions $[8,16]$. Added to this has been the patients' difficulty in expressing their own needs. Personality, cultural and historical differences may make mutual comprehension between patient and doctor very difficult.

Until recently, the effort made to bring together these two "realities" (the world of the doctor and the world of the patient) has resulted in an exponential increase in the number of instruments available. These instruments were created to evaluate quality of life, needs and satisfaction of care. A recent review of 210 published articles identified 18 potential need assessment standardized instruments used in cancer research [17].

A careful attention was given to improve psychometric proprieties of these instruments (reliability, validity, responsiveness). Less attention, on the other hand, was given to understand the deep meaning of what patients express when they report aspects of their quality of life, satisfaction and needs [18].

This kind of in-depth studies, which include an analysis of the patients' language and of the connotations and meanings of their words, may well represent a further approach to understanding the patients' conditions and their necessities, and may act as a guide for all those who administer care. The interest in patients' needs, and the meanings that patients give them, led to the setting up of a qualitative study parallel to a quantitative one on psychosocial and assistance-related needs of hospitalized cancer patients, with the aim of inducing interventions that satisfy the majority of their present needs.

The aim of the study was to evaluate different needs' prevalence in cancer inpatients and to understand their deeper meanings in order to promote an improvement in the quality of care. Secondary aims of the study were: a) to confirm the structural validity and the internal consistency of the standardized questionnaire used; b) to evaluate the association between the needs expressed and the basic demographic and clinical characteristics of the sample. 
Table I: Basic demographic and clinical characteristics of the sample of I 82 responders

\begin{tabular}{|c|c|c|}
\hline Characteristics & $\mathbf{N}$ & $\%$ \\
\hline \multicolumn{3}{|l|}{ Sex } \\
\hline Male & 90 & 49 \\
\hline Female & 92 & 51 \\
\hline \multicolumn{3}{|l|}{ Age } \\
\hline Median (range) & 60 & $21-89$ \\
\hline \multicolumn{3}{|l|}{ Educational level } \\
\hline Primary school & 60 & 33 \\
\hline Secondary school & 47 & 26 \\
\hline High school & 54 & 29 \\
\hline University & 13 & 7 \\
\hline Missing & 8 & 5 \\
\hline \multicolumn{3}{|l|}{ Primary tumor site } \\
\hline Head \& Neck & 35 & 19 \\
\hline Colon-rectum & 30 & 16 \\
\hline Breast & 20 & 11 \\
\hline Others & 94 & 52 \\
\hline Missing & 3 & 2 \\
\hline \multicolumn{3}{|c|}{ Number of previous admissions } \\
\hline None & 74 & 41 \\
\hline One & 45 & 25 \\
\hline Two or more & 63 & 34 \\
\hline \multicolumn{3}{|c|}{ Days of hospitalization (with regard to the present admission) } \\
\hline Median (range) & 7 & $3-13$ \\
\hline \multicolumn{3}{|c|}{ Autonomous movement } \\
\hline Yes & 166 & 91 \\
\hline No & 14 & 8 \\
\hline Missing & 2 & 1 \\
\hline
\end{tabular}

\section{Methods of the quantitative study Patients}

The survey was conducted in most clinical units at the Istituto Nazionale Tumori (INT) of Milan. The Units excluded were pediatric (as the questionnaire is to be filled out by adults) intensive therapy and nuclear medicine (as physical condition of the patients of such patients does not permit an easy interaction), medical and surgical dayhospital (as patients are admitted for too short a time). All patients admitted to the hospital at least 48 hours before, were invited to participate in the study and asked to give oral (informed) consent. Data regarding sex, age, educational level, primary tumor site, number of previous admissions and days of hospitalization were gathered. The NEQ (Needs Evaluation Questionnaire) was used for needs assessment [19].

\section{The Questionnaire}

The NEQ is a standardized questionnaire, consisting of 23 items, developed and validated at the Psychology Unit of INT (see table 2 for a detailed itemized presentation) [19]. It asks about different types of needs: information concerning diagnosis/prognosis (items 1 and 2), information concerning exams and treatment (items 3 and 4), commu- nicative (items $5-8$ ), and relational (items 20 - 22), which make up four distinct factors; twelve further single item scales related to assistance and treatment (items from 9 to 13), to structure (item 14), to financial aspects (items $15,16)$ and to support (items 17, 18, 19, 23) complete the questionnaire. The NEQ was administered by the members of the Psychology Unit, supported by volunteers from the Milan section of the Italian League Against Cancer, who also assisted the patients in filling in the questionnaire when help was requested.

\section{Statistical Analysis}

We compared groups of responders and non-responders with regard to demographic and clinical characteristics, using Fischer 's exact test and Student's t-test.

Confirmatory factor analysis on thetracoric correlation among the observed variables was used to test the structure of the questionnaire described above. Estimation of the model parameters was obtained by means of weighted least squares (WLS) using the program LISREL 8.0 [20]. Evaluation of the model to be confirmed was based on the following criteria: the Chi-square statistic $\left(\chi^{2}\right)$ [21], which indicates the lack of fit of the model (contrary to conven- 
Table 2: NEQ answers distribution missing data and reliability coefficients for each item $(\mathbf{N}=182)$

\begin{tabular}{|c|c|c|c|}
\hline Item number & Item text & $\%$ of Yes & $\%$ of missing data \\
\hline I & I need more information about my diagnosis & 40 & $\mathrm{I}$ \\
\hline 2 & I need more information about my future conditions & 61 & 2 \\
\hline 3 & I need more information about the exams I am undergoing & 35 & 0 \\
\hline 4 & I need more explanations on treatments & 32 & 1 \\
\hline 5 & I need to be more involved in the therapeutic choices & 30 & I \\
\hline 6 & I need clinicians and nurses to give me more comprehensible information & 32 & 0 \\
\hline 7 & I need clinicians to be more sincere with me & 20 & 0 \\
\hline 8 & I need to have a better dialogue with clinicians & 45 & I \\
\hline 9 & I need my symptoms (pain, nausea, insomnia, etc.) To be better controlled & 24 & 1 \\
\hline 10 & I need more help for eating, dressing, and going to the bathroom & 11 & 0 \\
\hline II & I need more respect for my intimacy & 18 & I \\
\hline 12 & I need more attention from nurses & 13 & I \\
\hline 13 & I need to be more reassured by the clinicians & 34 & I \\
\hline 14 & I need better services from the hospital (bathrooms, meals, cleaning) & 59 & I \\
\hline 15 & $\begin{array}{l}\text { I need to have more economic-insurance information (tickets, invalidity, etc..) } \\
\text { In relation to my illness }\end{array}$ & 40 & 3 \\
\hline 16 & I need economic help & 19 & I \\
\hline 17 & I need to speak with a psychologist & 17 & I \\
\hline 18 & I need to speak with spiritual assistant & 13 & I \\
\hline 19 & I need to speak with people who have had my same experience & 39 & 1 \\
\hline 20 & I need to be more reassured by my relatives & 12 & I \\
\hline 21 & I need to feel more useful in my family & 28 & 0 \\
\hline 22 & I need to feel less abandoned to myself & 18 & I \\
\hline 23 & I need to be less commiserated by other people & 19 & 2 \\
\hline
\end{tabular}

tional significance paradigms, large values of chi-square, and small P-values, indicate poor fit and model performance, leading to the rejection of the hypothesis that the assumed model is 'true'); the Adjusted Goodness of Fit Index (AGFI) [22], which, contrary to $\chi^{2}$ does not depend on sample size and measures how much better the model fits compared to no model at all (it should lie between 0 and 1, large values being associated to good models); the range of the Squared multiple Correlations (SMC) $[20,23]$ or each of the observed variables in the model (each index shows how well an observed variable serves as measurement instrument for the latent variable, with large values (range 0-1) being associated with good fit). Cronbach's alpha indexes [23] were calculated to estimate the internal consistency of the four factors tested.

Association between each of the 23 items of NEQ and sex, age, primary tumor site, educational level, number of previous admissions, self-sufficiency in movement and hospitalization duration was examined by means of Fischer's exact test for rxc tables or Student's " $t$ " test. Multiple comparison influence on Type I error was overcome by splitting the sample into two of equal size: the first, the "training" sample, was used to perform association analysis with an explorative aim and where $\mathrm{p}<0.10$ was considered significant; the second, the "validation" sample, was used to replicate the analysis and verify whether an as- sociation from the training sample still showed significance.

\section{Methods of the qualitative study}

The qualitative part of the study was aimed at complementing the quantitative description of the patients' needs, showing the multiplicity and richness of meaning that the affirmations of the questionnaire had in the subjective world of the individual patient. According with this aim, among the patients who filled out the questionnaire (NEQ), we choose a purposeful sub-sample (eight patients) identifying those who answered YES to more than five items and among them those who demonstrated great skill in recognising and expressing the experiences relative to their condition as admitted patient.

This kind of sampling focuses more on the identification of information-rich cases than on the representativeness [24]. The objective of the study is not to generalise the results but to show and document the complexity of an experience.

By means of individual semi-structured interview, the selected patients were invited to examine the meaning of the need they expressed through the questionnaire. 
The interview was constructed on the bases of the items of the NEQ questionnaire choosing those considered less deepened in the scientific literature or those who may lead to multiple interpretations by the patients.

The items were the following: $\mathrm{n} .2,5,7,11,13,17,18$ (the text of the items can be found in table 2). The interview started with the identification of a critical incident regarding the specific situation where the patient felt their needs been unsatisfied and, after this, the subjective meaning of the situation as well as the different implications of the needs were analysed and discussed. The interviews were tape-recorded and later transcribed.

Data analysis was carried out autonomously by three researchers, by means of successive steps, each of which represents an increasing level of generalisation:

- Each researcher identified all propositions held personally to be significant, without considering their relations with other parts of the text, accompanying them with his own comments.

- The comments were developed and contextualised along with the entire interview.

- From each interview the researcher extrapolated the themes he/she felt were relevant.

- Analyses of each interview were confronted with the others, with the aim of finding common themes and verifying conformities in similarity or contrast.

- The three analytic processes were confronted with one another.

The results were presented following the NEQ major factor groups obtained in the previous validation:

1. Information 1st factor: refers to information relative to diagnosis and future conditions.

2. Information 2 nd factor: refers to information on therapeutic choices and on results of tests.

3. Communication: predominantly regards relations with clinicians, in particular the feeling of being (or not) in a reassuring and sincere relation, based on dialogue.

4. Relational factor: regards the perception of patient's own position in a wider context (family, other patients, society in general).

5. The area of "intimacy" was also flanked beside these four factors.

\section{Results of the quantitative study}

Of the 224 eligible patients contacted in the sample day, $182(81 \%)$ fully completed the questionnaire, 2 partially completed it (more than 3 items missing), and 40 did not completed it at all. The reasons for non-completion were the following: refusal to fill out the questionnaire (8 patients), physical and/or cognitive difficulties (12 patients), absence of the patient from his/her ward for surgery or other exams (17 patients), other organizational problems (3 patients). The questionnaire was filled in by $49 \%$ of the patients unassisted, while the remaining $51 \%$ asked for assistance (the interviewer read the questions to the patient and then wrote down the answers, without exerting any influence on the responder).

Table 1 shows the basic demographic and clinical characteristics of the sample of 182 responders: 90 were males and 92 females, with a median age of 60 years and a medium-low educational level (59\%). $41 \%$ of them were at their first admittance in hospital, while 34\% had had 2 admissions or more, with a median duration of the current hospitalization of 7 days. The most common primary tumor sites were: head and neck (19\%), colon-rectum $(16 \%)$ and breast (11\%).

$91 \%$ of the patients were self-sufficient in movement. No statistically significant differences emerged between the group of responders and non-responders as regards gender, age, primary tumor site and duration of hospitalization, while they differed in number of previous admissions: responders had a mean number of 1.5 previous admissions $v s 0.7$ of non responders $(\mathrm{p}=0.018)$.

Table 2 presents the percentage frequency of positive answers and missing values for each item of the questionnaire. The percentages of missing values for each item are very low (range 0-3\%) indicating a good comprehensibility and acceptability of the questionnaire by the responders. Among the five requests most frequently expressed by the patients, four regard information needs: concerning diagnosis $(40 \%)$, about future conditions (61\%), regarding a better dialogue with clinicians (45\%), and about economic-insurance information (40\%), while only one regarded the need for better services at the hospital (bathrooms, meals, cleaning) (59\%).

Most of the support-assistance items remain under 30\%. The need that was less frequently expressed concerned help for eating, dressing, and visiting the bathroom $(11 \%)$, which is in accordance with the characteristics of a very low percentage of the sample presenting problems on movement. There was also a low level of request for better attention from nurses (13\%). 
Table 3: Standardized Lisrel estimated factor loading for the validated model

\begin{tabular}{ccccc}
\hline Item number & Informative Ist $\left(^{*}\right)$ factor & Informative 2nd (**) factor & Communicative factor & Relational factor \\
\hline 1 & 0.99 & - & - & - \\
2 & 0.78 & - & - & - \\
3 & - & 0.96 & - & - \\
4 & - & 0.99 & - & - \\
5 & - & - & 0.92 & - \\
6 & - & - & 0.97 & - \\
7 & - & - & 0.93 & - \\
8 & - & - & - & 0.90 \\
20 & - & - & - & 0.84 \\
21 & - & - & - & 1.00 \\
22 & - & - & 0.76 & 0.64
\end{tabular}

$(*)$ Information needs about diagnosis and prognosis. $(* *)$ Information needs about exams and treatments.

The confirmatory construct analysis showed that the model tested (on the four factors described in the methods) provides a good fit to the data $\left(\mathrm{P} \chi^{2}=0.136, A G F I=0.98\right.$, and range SMCs: 0.61-0.99). Table 3 presents the standardized Lisrel estimated for the factor loading of the model tested, all of which are significantly different from zero at $\mathrm{P}<0.001$. Cronbach's alpha indices for the four factors tested were $0.63,0.76,0.76,0.64$ respectively, showing acceptable to good levels of internal consistency.

None of the association which proved statistically significant on the training sample was confirmed by the analysis on the validation sample. Since the power of tests performed may have been greatly limited by the splitting of the sample for the training and testing procedure, some of the associations thought not statistically significant which maintain their direction in both samples ought to be verified in future studies. The above associations indicate that, as the number of previous admissions grows, the level of information needs (all items except for better dialogue with doctors and better attention from nurses) diminishes; further, that the higher the educational level, the lower the need for economic help.

\section{Results of the qualitative study}

The original expressions of the interviewees are reported in tables $4,5,6,7,8,9$, grouped into thematic areas corresponding to the principal factors of NEQ.

Table 4 shows the need to obtain a diverse modality of communication between clinician and patient, and to redefine the setting in which this traditionally takes place. In addition, table 5 shows the need for making the scenario of a patients' future life intelligible and foreseeable; patients ask for personalized explanations shaped as much as possible to their individual needs, thus avoiding inde- terminacy or generalization based on statistical reference or analysis. According to table 6 clinicians are requested to understand the patients' demands even though these demands are not always consonant with the clinician's own perspective on therapeutic choices. A less hurried, hermetic, and prudent, and a more sincere and polite form of communication was also requested (table 7). Some patients brought to attention the potential danger of communication between hospitalized patients themselves, through which anxiety might be exacerbated among "the deaf", rather than any reassuring exchange of experiences and reciprocal encouragement occurring (table 8). The patients' reflections on the theme of intimacy (table 9) considered in all its multiple of facets - refer, among other things, to criticism of situations like the "doctors' rounds", perceived as a violation of the some of the most elementary principles of respect for privacy.

\section{Discussion}

The analysis of the structural validity and the internal consistency of NEQ confirmed the psychometric properties shown in our previous study giving a further evidence of its value in assessing hospitalized patients' needs.

This study shows that some needs are unsatisfied in one out of two hospitalized cancer patients. Most of the needs concern the request to receive more information both about their future conditions (this is the most expressed need, reported by 6 patients out of 10) and their diagnosis ( 4 out of 10). These findings agree with data already reported [17,25-27]. Besides the documented presence of this two needs and the importance of information in the doctor-patient relationship, some studies have underlined the necessity that clinicians help patients to understand information $[25,28,29]$. 
Table 4: Factors I. Information. Items: I need more information on my diagnosis; I need more information on the exams I am undergoing; I need more information on treatments

\section{The Pros and Cons}

In my opinion having information on my disease means knowing all there is to know about the illness. Knowing what are the pros and cons: what you can do after the operation, how my life and my eating habits will change; and what the effects will be of therapy. Knowing everything - no. Knowing everything would hurt you. But knowing the most important things is indispensable.

\section{The Doctor's Round}

Take the Doctor's Rounds in the morning when they tell us how the tests went or they sum up to that moment. In that time, I need information; but often this 'round' is characterized by a Hermetic language. I, at least, understand a little, thanks to my scientific background. Then they are extremely laconic when it comes to the outcome of a test that could determine a change of therapy because the result is less positive than expected. So I would say that not only do more things need to be said, but things need to be explained in more detail so that they can perhaps reassure the patient as to why such and such a test did not go so well.

But in a few words they tell you that the previous therapy did not have a great effect, that the results of the last exam showed a lack in efficacy, and so therapy must be changed.

\section{Percentages}

Not long ago, after six months of being cured, they told me that this kind of therapy improved my cancer by $40 \%$. They told me this was an extremely positive result because I.) I had been getting worse and so the tendency was reversed. And 2.) for them, $40 \%$ was a lot; I was very distraught because I had thought that after six months of very heavy therapy, $40 \%$ for me was very little. Therefore not only did they not obtain the response they" desired" from me in communicating the result, but I was thinking that another 6 months of therapy was going to be necessary.

They communicated this to me with satisfaction; but considering how much I had suffered up until that moment and considering how long the therapy took, thought the result was poor. From their medical point of view probably my observation was seen as unreasonable. What for them was a good result lost all meaning and became demoralizing for me when it reached me as simply a number.

\section{Percentages I}

The idea of calling a doctor for a response in terms of percentages is not the kind of answer I would like. Yes, I would like to know I had lost about half the hair on my head; or that in a certain percentage of cases the stomach resumes its normal functions with great difficulties which need to be progressively overcome. This way of answering I consider to be fully satisfactory.

Percentages 2

"He/she told me straight away: 'In $80 \%$ of cases, these are things that cure.... You are in the other $20 \%$. This means that you are unlucky...."'.

Table 5: Future Conditions. Item: I need more information on my future conditions

\section{Quality of Life}

By 'future' I mean also the quality of life because someone can say "you will live for 10 years", but "how will I live?". More detailed information is needed; like, for example: "you must cope with this or that"; but doctors just give summarized information. This is true above all about oncologists.

Also I mean the possibility of being cured, but here everything is reported in statistical terms; it is very schematic: "50\% responded like that; $30 \%$ like this". But no one knows what their own percentage will be. They don't consider your own case. This case must be considered; for with the same disease one patient may be in a bad state, while another feels OK. They cannot be equal; this should be considered. But they only consider the state of the disease and everything is related to that.

They tend not to speak. They don't open up. If you continue to ask questions maybe you will hear things said that you wouldn't want to hear. The answer, beyond a certain point, is not stimulating but soul destroying. It is worth asking questions, but only up to a certain point.

\section{Length and Quality of Life}

For me it is more important to think "the years that I have left to live will have a certain quality of life," rather than "I have so and so many years to live".... of course. While before I, who had never been ill, used to think that nothing could happen to me or, rather, I took it for granted instead of thinking about it, now, I don't take anything for granted and this illness changes my life a lot. You have to re-see everything. However, you lose 2 years of your life. You can see it is impossible to keep your old job, your place of responsibility, and then you choose to have a life different from the one before. You try to analyze what didn't go well before. I, now, would remedy a certain degree of superficiality of my old life. I am very attentive now; much more of my attention is focused on many things; many signs. Before, I used to pass over things that were important; things that would always be done 'afterwards'. Now I make different choices; of course I would not neglect so many signs any more. This cancer was discovered by chance; I had completely neglected to heed certain messages my body communicated to me...

\section{Things Precise and Nearby}

I feel great discomfort as I go along this winding path that changes from time to time; and from time to time my future conditions also change. From time to time cloudy and uncertain information is given to me, probably because my response to treatments is cloudy and uncertain; however, my future conditions are completely dependent on contingencies.

It's not about a far off future, but about things precise and nearby. 
Table 6: Factor 2. Involvement in Therapeutic Choices. Item: I need to be more involved in therapeutic choices

\begin{abstract}
Adaptive to My Demands
For me, choosing the therapy together with a doctor means knowing what I will be up against with the therapy that the doctor decides to give me. And speaking about it together with him/her could help to find a more adaptive solution to my demands, perhaps changing a little of what he/she might administer to me. It would be good to be able to come up with a 50:50 understanding arrangement where I understand the doctors' demands who wishes to use therapy on me, and where he/she understands my demands too. Up to now I haven't taken part in such an arrangement.

The Choice

It is clear that therapeutic choice should be made by the doctor because I am not a doctor. However, the doctor must explain the purpose of the therapy he/she adopts so that I can make a distinction too. The doctor should make the choice, but he/she should also "listen" if the patient is willing to go through with such a choice. He/she should say: 'I propose this for this reason.' And I, who am the person directly involved will say: 'Yes. That's ok for me because I understand what it's supposed to do!
\end{abstract}

Table 7: Factor 3. Communication. Items: I need doctors to be more sincere with me; I need to have more dialogues with doctors; I need to be more reassured by doctors

\begin{abstract}
Hermetic Communication
Communication with the patient is hurried and fairly hermetic also for a person of average cultural background. Therefore given that this is an illness which has important psychological implications, communication in 'snatches' will not do.

Communications are given in a very formal context (the 'round'), but it is obvious that for the patient it is more difficult to ask for explanations from 10 doctors instead of just one.

They give the impression of speaking in abbreviations. They speak to one another about the results of tests in such a condensed way that it almost gives the impression they don't want to communicate to the patient at all; that the information is more or less for their own internal use. Sometimes they give contradictory information among themselves (depending on the doctor) and this worsens the situation. One time I said to one of them that because patients have so little time available (with the doctors) their 5 minutes of explanation in the morning is meditated on later on in the day, sometimes during the whole day, so they can try to interpret what was said. The doctor's reply was that they are so involved in a whole series of practical problems, urgencies, that they don't rate this aspect and that if they weren't made to observe it a second time they wouldn't even be aware of the damages that some of their words could cause to the patient. For me a more interactive, more simple and human situation needs to be created. First of all maybe it is necessary that there be one same version in the sense that sometimes three different doctors come and each one gives a different version of the same exam; this naturally doesn't help. And, apart from this problem, the way in which these communications are expressed is not like a dialogue, but like an authoritative lecture. And more often than not, it is expressed not for communication with the patient, but for communication among the specialists themselves in which the patient is lucky if he/she understands anything at all; otherwise... see you in another moment; maybe after three days.
\end{abstract}

Politeness First and Foremost

I have had the experience of being admitted to hospital wards in other institutions. There are enormous differences: in one of the two cases, no doctor came. Things were allowed a little to be like that. But a doctor coming and stopping for a time to speak to the patient is extremely important for me; otherwise people feel rather abandoned...I was there for what should have been three days; and then in one week I saw one doctor only pass by once. He was the consultant surgeon. The consultant surgeon didn't say hello; he didn't ask patients what they had. No - he asked the swarm of practitioners - young doctors who were learning - instead! I heard someone answer about my case: "He had a problem, but now it's been resolved!" But what problem? Why doesn't he ask me what I had? I was there for that mistaken experience .... Because they had made a mistake in a certain kind of operation... Then they moved on, without saying hello, without making eye contact.

This is lack of politeness first and foremost. I saw that they acted like this with all the beds in the room. This surely must be improved upon.

Sincerity

Sincerity is something one realizes subsequently; for, during the moment when it is verified that the things the doctor said really are what he said they would be, one understands a posteriori the sincerity of the doctor. A priori, a stronger act of trust is needed; for this it is important to have an empathetic rapport with patients.

The patients' desire to know more about their own diagnosis and future conditions does not necessarily mean that the patients ask for an active role in medical decisionmaking. Less than a third of patients expressed the request for deeper involvement in therapeutic choices. Two recent studies on women with breast cancer gave similar results; about half of the women had a role in decision-making that matched their desired role, a quarter had a less active role than desired, and a quarter had a more active role than desired $[30,31]$.

The new trend that encourages self-determination and responsibility by the patients did not, in fact, take into account patients' disorientation, and therefore their inability to take at times a more active role in the management of their experience with the disease. The clinicians find themselves lacking guidelines for managing doctor- 
Table 8: Factor 4. Relational. Items: I need to talk to people who have had my same experience; I need to be more reassured by my family and relations; I need less commiseration from others

\section{Dialogue Among Patients}

Often what takes place among patients is a dialogue among 'deaf' (sic) people; for most of the time they don't listen to the others. They only have this need to communicate the horror that they are experiencing; a whole series of somber heavy feelings which, in that moment, they absolutely need to communicate and they don't even listen to what the other person is saying; so there is no real conversation. There is a passing of information; there is an irresistible urge to broadcast, to communicate. I often go to have breakfast in a common area and I hear myself asking 'Where do you have your cancer?' before asking me: 'What's your name?' or 'Where do you live?'. It is really absurd, but justified because I feel the fear that lies behind it and the necessity for recounting one's own story. It is an irresistible necessity; within about half an hour you can discover just about everything about such and such a person; and not only his/her illness, but also everything else that person had experienced previously.... But everything is centered on the disease, with extreme heaviness, with an extreme sense of claustrophobia.

By now l've got to the point where I listen to my walkman so as to avoid communication, so as not to listen to what the others are saying, and so as not to be involved in conversations with those who pretend to be interested in your disease, but who really wish to speak about their own.

\section{The Rest of the World}

The fact of being a cancer patient makes people enter into a role and makes them always speak about the same things. It makes others assume the belief that the rest of life, also of their life, is useless when faced with the gravity of the experience the patient is undergoing. There exists a disproportion. At times others, also friends, refuse to recount their things because of this disproportion of pain in mind; and this prevents the rapport from being on an equal level. Patients are seen as poor little animals who are 'people truly with a problem'; while the rest of the world has silly and inessential problems. This, therefore, causes others to always speak of the same things. So they speak not only of such and such a disease, but of everybody else's disease as well. What a nice catalogue of disasters and misfortune!! To sum up: our problems are vain; they're silly; they're frivolous; only you have true problems; let's speak only about your problems.

Table 9: Intimacy. Items: I need more respect for my intimacy; I need more attention from the nursing staff; I need better services from the hospital (bathrooms, meals, cleaning)

\section{A Very Physical Presence}

I found the nursing staff reasonably attentive. I remember there being a very physical presence. Maybe if we understand it in a wider context, the fact of sharing living space with another person... well...this could be a violation of intimacy. Undergoing certain particularly heavy therapies while sharing your room with another person can, at times, create situations lacking in intimacy which only makes everything heavier to bear.

Involuntary Hearing

For example, when doctors come along on their rounds - I am in a room with four beds - it annoys me to hear everything about other people's diseases; just as it annoys me when the others hear things about my situation.

I don't think this is right. I feel uncomfortable when I can't get up because usually when the doctor finishes speaking to me I leave; but I have found myself in situations where I couldn't get up; where I had to stay there and listen to the doctor who maybe said some things which were a little unpleasant to another patient and I felt the patient's state of being ill at ease; he/she maybe felt embarrassed; maybe he/she couldn't express what he/she wanted to. I have noticed this both in myself and in other persons.

\section{Being Seen Naked}

...I mean, above all, the fact of being seen naked... Situations do exist where nurses wash a woman in the same room in front of you; or where a male nurse comes to wash you because it's his shift and involuntarily it wasn't thought of to send a female nurse.

\section{Sensitivity}

...for example, when a person has a stoma and a person needs to be clean; because if you are operated on you shouldn't have to go and beg to the nursing staff for them to change you; it should be a logical thing; immediate. I have found myself having to beg for this. If I had been capable I would have done it myself. This touches a person deeply, for it is his/her way of feeling, of being sensitive. Intimacy is not represented only by certain things, but it also consists in moving to touch a person in the area where he/she feels; touching his/her sensitivity.

Sensitivity is a very intimate property (part) of a person.

\section{Dividing Men and Women}

From the point of view of one's own intimacy, it is an infamy state of affairs. Last night I went in to the bathroom and there was a gentleman there: I felt inhibited. The doors don't close properly. And, anyway, I didn't particularly feel like going into the bathroom and seeing that man cleaning his set of false teeth. Again, one can't get undressed in order to wash properly. These are things that make you feel bad.

They could, at least, divide men and women: at least then (for me) it would be only women encountering one another in the bathroom.

patient relationships. The traditional paternalistic doctorpatient relationship is no longer acceptable; however, the basis of a new clearer and "shared" model has yet to be found.
Clinicians should, therefore, consider the meanings (explicit and implicit) contained in a request for more information. The analysis of qualitative data of the study shows that the need for more information on their future conditions does not mean for patients "knowing all there is to 
know about prognosis". The patients' principal need appears to be receiving more information about the impact of their illness and treatment on their daily lives, with particular attention being paid to the realistic ability to carry out such activities; in brief "what will I be able to do or not do?", "what will I or won't I be able to eat?", "will I be able to move, work, love, have children and if "yes", how?". One important dimension, therefore, regards the quality and not just the quantity of life remaining. The appropriate care for patients will be the one that also considers the implications of the illness, and is capable of providing patients with assistance for the diverse problems [7].

Another aspect which emerges from the analysis of qualitative data concerning information on prognosis, regards the quantification of the risks of the therapy proposed by the doctor. In the quantification of the uncertainty of evolution and efficacy of a cure, the epidemiological and statistical tools might precisely and accurately render the expectations for a patient with similar characteristics without being able to give a deterministic estimation in specific cases. On the other hand it appears that it is more important for the patient to a) receive personalized information, which is commensurate with his/her physical and emotional situation, and b) to be considered within his/ her own unique profile. Thus "expected time" can be different from "lived time", where the days and nights are diverse, some terrible, others welcoming, others without identity but all intrinsically offering some quality of life.

Furthermore, patients' observations suggest the necessity of an improvement regarding the circumstances under which personal information is discussed. Crowded, noisy ambulatory conditions too often provide the stage for delicate and important communications. Patients respond negatively also to "the doctor's round" on the ward; they are aware of being the object of the clinicians' deliberations and they feel inhibited about open communication.

The request for more dialogue, expressed by around half of the patients, emphasizes the importance of communication and listening skills necessary for selecting information considered relevant by patients. The clinician-patient relationship should, therefore, encompass and integrate listening more attentively to these expressed needs, and the provision of information. It should be a connection between the world of cancer as a 'biological entity' (disease) and the world of cancer as 'a lived experience' (illness). It is within this kind of relationship that the patients will find greater assurance. It will allow the patient to feel that the doctor is nearer to him/her about any future eventuality.
The need for reassurance is expressed by 4 patients out of 10 , together with the desire to talk to people who have had similar experiences. Relations among hospitalized patients, however, are complex. Analysis of our qualitative data shows that the relationships between such patients cannot always be simply defined as "having company" or "sharing similar experiences"; it can also represent a moment of emotional engagement. Confrontation with others may sometimes generate an element of 'contagion'. Repartitioning of physical space in hospitals should, therefore, take into consideration the necessity for the setting up in some cases of protected areas in which the patient can expect intimacy.

The need for a more respect of intimacy (present in only 2 patients out of 10) appears to be not only manifested by patients being seen naked, or by their forced sharing of bathrooms. The patient is usually subordinated and in a weak position with regard to the rules and regulation of hospitalization that, at times, fails to respect their intimacy and privacy.

One last, but by no means least, aspect is the satisfaction of needs regarding services offered by the institution, both concerning assistance (control of symptoms and/or of practical help with functional problems) and hotel services (bathrooms, meals and cleanliness). While there seems to be little presence of needs concerning assistance and most patients are satisfied with hospital staff, the needs concerning hotel services were expressed as being not satisfactory by two patients out of three, indicating the need to improve these services.

The 'humanization movement' in hospitals, which in recent years is definitively culturally based, will be accomplished not only through education and training processes of health workers, but also by structural interventions aimed at rendering the experience of hospitalization more amenable and comfortable for patients [32].

It is difficult to evaluate the real impact of this research to meet the needs of the patients of our hospital. Preliminary data from this study were presented at a meeting of a large number of physicians and nurses working in the hospital. The data was commented upon by the directors and the members of the Ethical Committee of the hospital. The solutions suggested to meet the needs expressed by patients were published in the newsletter and the web site of the Institute, followed by articles on the Volunteer organizations, patients' right Associations newsletters and by popular magazines. This could be a first step in the direction of real change in cancer patient care.

\section{References}

I. Engel GL The need for a new medical model: a challenge for biomedicine Science 1977, 196:129-36 
2. Engel GL The clinical application of biopsychosocial model Am J Psychiatry 1980, 137:535-44

3. Preamble to the Constitution of the World Health Organization as adopted by the International Health Conference, New York, 1922 June, 1946; signed on 22 July 1946 by the representatives of 61 States (Official Records of the World Health Organization, no. 2, p. 100) and entered into force on 7 April 1948

4. Lazarus RS Stress and coping as factors in health and illness In: Psychosocial aspects of cancer (Edited by: CJ Cohen J, Martin LR) New York: Raven Press 1982,

5. Degner $L$ and Sloan JA Decision making during serious illness: what role do patients really want to play? J Clin Epidemiol 1992 45:94I-50

6. Maguire $\mathrm{P}$ Improving communication with cancer patients Eur J Cancer 1999, 35:1415-22

7. Gerber LH Cancer Rehabilitation into the future Cancer 200I, 92(S):975-9

8. Bakker D, DesRochers C, McChesney C, Fitch M and Bennet J Community cancer clinics: patients' perspectives Support Care Cancer 200I, 9:234-40

9. Suchman Al, Markakis K, Beckman HB and Frankel R A model of empathic communication in the medical interview Jama 1997 277:678-82

10. Guadagnoli $E$ and Ward P Patient participation in decision making Soc Sci Med 1998, 47:329-39

II. Derogatis LR Psychometric issues in the psychological assessment of cancer patients Cancer 1984, 53:2228-32

12. Ware JR Conceptualizing disease impact and treatment outcomes Cancer 1984, 53:2316-23

13. Aaronson NK and Beckmans J The quality of life of cancer patients New York: Raven Press 1987

14. Italian Psycho-Oncology Society, (SIPO). Consensus development conference: Assessment of the quality of life in cancer clinical trials Tumori 1992, 78: $151-4$

15. Mor $V$ and Guadagnoli $E$ Critique of psychosocial and behavioral measurement in cancer research In: Current concepts in PsychoOncology and AIDS (Edited by: MJ Holland JC, Lesko LM) New York 1987

16. Sutherland HJ, Lockwood GA and Boyd NF Ratings of the importance of quality of life variables: therapeutic implications for patients with metastatic breast cancer J Clin Epidemiol 1990, 43:66I-66

17. Gustafson D Needs Assessment in Cancer In: Outcomes Assessment in Cancer (Edited by: Snyder CF) Cambridge: Cambridge University Press

18. Leplege $A$ and Hunt $S$ The problem of quality of life in medicine Jama 1997, 278:47-50

19. Tamburini M, Gangeri L, Brunelli C, Beltrami E, Boeri P, Borreani $C$ Fusco Karmann C, Greco M, Miccinesi G and Murru L Assessment of hospitalised cancer patients' needs by the Needs Evaluation Questionnaire Ann Oncol 2000, II:31-7

20. Jöreskog K and Sörbom D LISREL 8: User's reference Guide Chicago: Scientific Software International 1996,

21. Bentler PM and Bonnet DG Significance tests and goodness of fit in the analysis of covariance structures Psycol Bull 1980, 88:588606

22. Tanaka JS and Huba GJ A fit index for covariance structure models under arbitrary GLS estimation $\mathrm{Br} J$ Math Stat Psychol 1985, 42:233-9

23. Cronbach $L$ J Coefficient alpha and the internal structure of test Psychometrica 1951, 16:197-334

24. Crabtree BF and Miller WL Doing qualitative research London: Sage Publications 1992,

25. Harris KA The informational needs of patients with cancer and their families Cancer Pract 1998, 6:39-46

26. Leydon GM, Boulton $M$ and Jones $A$ Cancer patients' information needs and information seeking behaviour: in depth interview study Bmj 2000, 320:909-13

27. Degner LF, Kristjanson LJ, Bowman D, Sloan JA, Carriere KC, O'Neil J, Bilodeau $B$, Watson $P$ and $B$. M Information needs and decisional preferences in women with breast cancer Jame 1997, 277: | 1485-92

28. Cooley ME, Moriarty H, Berger MS, Selm-Orr D, Coyle B and Short $T$ Patient literacy and the readability of written cancer educational materials Oncol Nurs Forum 1995, 22:|345-5|
29. Meredith P Patient satisfaction with communication in general surgery: problems of measurement and improvement Soc Sci Med 1993, 37:59I-602

30. Bruera E, Willey JS, Palmer JL and M. R Treatment decisions for breast carcinoma: patient preferences and physician perceptions Cancer 2002, 94:2076-80

3I. Keating NI, Guadagnoli E, Landrum MB, Borbas C and Weeks JC Treatment decision making in early-stage breast cancer: should surgeons match patients' desired level of involvement? ] Clin Oncol 2002, 20: I473-9

32. Oswald WW Creating a service culture Healthc Exec 1998, 13:64-5

\section{Pre-publication history}

The pre-publication history for this paper can be accessed here:

http://www.biomedcentral.com/1471-2407/3/12/prepub
Publish with Biomed Central and every scientist can read your work free of charge

"BioMed Central will be the most significant development for disseminating the results of biomedical research in our lifetime. "

Sir Paul Nurse, Cancer Research UK

Your research papers will be:

- available free of charge to the entire biomedical community

- peer reviewed and published immediately upon acceptance

- cited in PubMed and archived on PubMed Central

- yours - you keep the copyright
BioMedcentral 